\title{
Ocorrência de Fusarium solani f. sp. piperis em Piper nigrum no estado de Alagoas
}

\author{
Juliana Paiva Carnaúba ${ }^{1}$, Márcio Félix Sobral ${ }^{2}$, Edna Peixoto da Rocha Amorim³ ${ }^{3}$ Izael Oliveira Silva ${ }^{4}$
}

${ }^{1}$ Estudante de Mestrado em Agronomia, CECA-UFAL/ Bolsista CAPES. ${ }^{2}$ Estudante de Agronomia, CECA-UFAL/ Bolsista CNPq. ${ }^{3}$ Universidade Federal de Alagoas, Centro de Ciências Agrárias, Departamento de Fitotecnia e Fitossanidade, CEP 57100-000, Rio Largo, AL. ${ }^{4}$ Estudante de Mestrado em Agronomia, CECA-UFAL/ Bolsista Fapeal. E-mail: jcarnauba@ hotmail.com Autor para correspondência: Juliana Paiva Carnaúba

Data de chegada: 19/09/2005. Aceito para publicação em: 04/04/2006.

\section{RESUMO}

Carnaúba, J.P.; Sobral, M.F.; Amorim, E.P. da R.; Silva, I.O. Ocorrência de Fusarium solani f. sp. piperis em Piper nigrum no estado de Alagoas. Summa Phytopathologica, v.33, n.1, p.96-97, 2007.

A pimenta-do-reino (Piper nigrum L.) é uma planta trepadeira, pertencente à família Piperaceae. Ela é originária do Sudeste Asiático, sendo a mais comum e importante das especiarias. A fusariose, também conhecida por podridão do pé e podridão das raízes é a principal doença da cultura, de ocorrência restrita ao Brasil. Um isolado de Fusarium sp., encontrado infectando plantas de pimenta-do-reino cv. bragantina no município de União dos Palmares em Alagoas, foi caracterizado morfologicamente e teve sua patogenicidade confirmada em mudas deste hospedeiro. Os macroconídios apresentaram-se falcados, hialinos com três a cinco septos, com dimensões de 30,5 - 26,5 x 6,3 - 4,9 ìm, enquanto os microconídios apresentaram-se hialinos, unicelulares, elípticos ou alantóides medindo 16,6 - 4,9 x 6,5 - 3,3 ìm. Os clamidósporos foram abundantes em meio batata-dextrose-ágar. O isolado foi identificado como Fusarium solani f. sp. piperis Alb. tratando-se do primeiro relato deste patógeno em pimenta-do-reino no estado de Alagoas.

Palavras-chave adicionais: Fusariose, etiologia, pimenta-do-reino.

\section{ABSTRACT}

Carnaúba, J.P.; Sobral, M.F.; Amorim, E.P. da R.; Silva, I.O. Report of Fusarium solani f. sp. piperis in Piper nigrum in the state of Alagoas. Summa Phytopathologica, v.33, n.1, p.96-96, 2007.

The pepper-of the-kingdom (Piper nigrum L.) it is a climbing plant, pertaining plant to the Piperaceae family. It is originary the southeastern Asian, being most common and important of the spices. Seedling death, also known for rottenness of the foot and rottenness of the root is the main illness of the culture, restricted occurrence to Brazil. Isolated of Fusarium sp., found contamined plants of bragantina pepper-do-kingdom cv. in the city of União dos Palmares in Alagoas, was characterized morphologycament and had its pathogenicity confirmed in changes of this host. The macroconidia slightly curved, typically canoe-shaped, hyaline with three the five septate, measuring 30,5 - 26,5 x 6,3 - 4,9 ìm. Microconidia hyaline, unicellulars, ellipticals or allantoises measuring $16,6-4,9 \times 6,5-3,3$ ìm. The chlamydospores had been abundant in half potato-dextrose-agar. The isolated one was identified as to Fusarium solani f. sp. piperis being about the first story of this parasitic on plants in pepper-of the-kingdom in the state of Alagoas.

Additional keywords: seedling death, etiology, pepper-of the-kingdom

A pimenta-do-reino (Piper nigrum L.) é uma planta trepadeira, pertencente à família Piperaceae. Ela é originária do Sudeste Asiático, mais precisamente da Índia, sendo a mais comum e importante das especiarias (2). É uma das espécies que apresenta um curto período de imaturidade, iniciando a produção comercial a partir do segundo ano. No entanto, a pimenta-do-reino (Piper nigrum) é muito suscetível ao fungo Fusarium solani f. sp. piperis Alb., causador de grandes danos à cultura, reduzindo o período útil de exploração da cultura para apenas quatro anos.

A fusariose, também conhecida por podridão do pé e podridão das raízes é a principal doença da cultura, de ocorrência restrita ao Brasil (4). As medidas que vêm sendo adotadas para o controle da fusariose, como práticas culturais, obtenção de variedades resistentes e aplicação de fungicidas $(1,3)$, têm-se mostrado onerosas ou pouco eficientes.

Em março de 2005, em uma propriedade no município de União dos Palmares - AL, constatou-se a ocorrência de podridão das raízes infectando plantas de pimenta-do-reino cv. bragantina de aproximadamente 3 anos de idade (Figura 1A). O objetivo deste trabalho foi identificar o agente causal da podridão das raízes em 


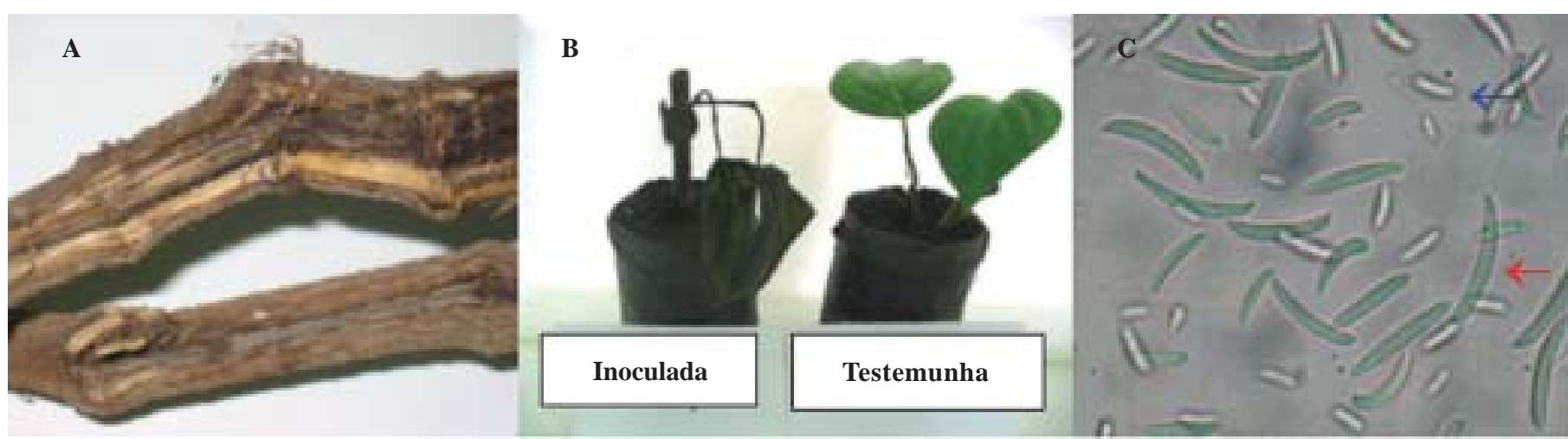

Figura 1. Fusarium solani. (A) corte longitudinal no caule da planta: escurecimento dos vasos; (B) Teste de patogenicidade - 12 dias após inoculação; (C) Conídios de Fusarium solani: Macroconídios (૯) e Microconídios (૯).

plantas de pimenta-do-reino.

Para o isolamento de Fusarium sp., empregou-se o meio batatadextrose-ágar (BDA) contendo inibidores seletivos. As culturas foram incubadas a $28^{\circ} \mathrm{C}$.

O teste de patogenicidade foi realizado em dez mudas de pimenta-do-reino de aproximadamente quatro meses de idade, através do método de suspensão de esporos ( $10^{6}$ conídios/ $\mathrm{mL}$ ), enquanto as testemunhas receberam apenas água destilada e esterilizada. As plantas inoculadas e as testemunhas foram mantidas em câmera úmida por $48 \mathrm{~h}$ à temperatura ambiente.

As plantas inoculadas apresentaram sintomas de murcha após o $12^{\circ}$ dia, enquanto as testemunhas permaneceram sadias (Figura 1B). As culturas reisoladas em meio BDA foram semelhantes às originais, confirmando a patogenicidade do isolado.

O isolado foi caracterizado com base na morfologia e dimensão das estruturas reprodutivas, em lâminas observadas ao microscópio em aumento $40 \mathrm{X}$ por meio de 50 observações de cada. Os macroconídios apresentaram-se falcados, alguns quase retos, hialinos com três a cinco septos, com dimensões de 30,5 26,5 x 6,3 - 4,9 ìm ( $\mathrm{x}=31,7$ x 5,7 ìm), enquanto os microconídios apresentaram-se hialinos, unicelulares, elíticos ou alantóides medindo 16,6 - 4,9 x 6,5 - 3,3 ìm ( $\mathrm{x}=10,6$ x 4,5 ìm), estando de acordo com as descrições de Kimati (4). Os clamidósporos foram abundantes em meio BDA formados principalmente ao pares, concordando com Menezes (5).
Este foi o primeiro relato de $F$. solani em Piper nigrum no estado de Alagoas.

\section{AGRADECIMENTOS}

Os autores agradecem ao Sr. Tagore Carnaúba Acioli (in memoriam) pelas mudas de pimenta-do-reino cedidas e por toda sua atenção.

\section{REFERÊNCIAS BIBLIOGRÁFICAS}

1.Ando, A.; Albuquerque, F.C.; Poltronieri, M.C.; Tulmann Neto, A. Obtenção de mutantes resistentes a fusariose (Fusarium solani $\mathrm{f}$. sp. piperis) em pimenta-do-reino através de irradiação gama. In: Seminário Internacional Sobre Pimenta E Cupuaçu, 1., 1996, Belém. Anais. Belém: Embrapa-CPATU/JICA, 1997. p.237-243. (Embrapa-CPATU. Documentos, 89);

2.Costa, R.S.C.; Medeiros, I. M. Pimenta-do-reino. Porto Velho: EMBRAPA Rondônia, 2000. 6p. (EMBRAPA Rondônia, Folder);

3.Duarte, M.L.R.; Albuquerque, F.C. Eficiência de diferentes fungicidas no tratamento de estacas de pimenta-do-reino (Piper nigrum L.) infectadas por Nectria haematococca (Fusarium solani f. sp. piperis). Fitopatologia Brasileira, Brasília, v.6, n.2, p.169-175, 1980;

4.Kimati, H.; Amorim, L.; Bergami, A. Filho.; Camargo, L.E.A.; Rezende, J.A.M. Manual de Fitopatologia: Doenças das plantas cultivadas. 3.ed. São Paulo: Agronômica Ceres Ltda, 1997. 725p;

5.Menezes, M. \& Oliveira, S.M.A. Fungos Fitopatogênicos. UFRPE. Recife-PE. 1993. 